\title{
Contraception Matters: Two Approaches to Analyzing Evidence of the Abortion Decline in Georgia
}

\begin{abstract}
CONTEXT: The abortion rate in the republic of Georgia is the highest documented in the world. Analyses using reliable data are needed to inform programs for preventing unintended pregnancy and abortion.

METHODS: Data from two large national household surveys conducted in 1999 and 2005 were used to assess the relationship between contraceptive use and abortion. Two analytic approaches were used. First, abortion rates were estimated for three subgroups: users of modern contraceptives, users of traditional contraceptives and nonusers of contraceptives. A decomposition method was then used to estimate the proportions of change in abortion rates that were due to changes in contraceptive use and to changes in use- and nonuse-specific abortion rates. Second, a methodology developed by Westoff was used to examine abortion rates among contraceptive users and among nonusers with differing risks of unintended pregnancy.
\end{abstract}

RESULTS: According to data from the 60 months before each survey, contraceptive prevalence among married women increased by $23 \%$ (from 39\% to 48\%) and the marital abortion rate declined by 15\% (from 203 to 172 abortions per 1,000 woman-years) between 1999 and 2005. Both approaches showed that nonuse of any method was the principal determinant of the high unintended pregnancy rate and that the increase in use of modern contraceptives was a significant contributor to the recent drop in abortion (explaining $54 \%$ of the decline, according to the decomposition analysis).

CONCLUSIONS: Efforts to increase availability and use of modern family planning methods in Georgia should lead to a direct and measurable decline in the abortion rate.

International Perspectives on Sexual and Reproductive Health, 2010, 36(2):99-110

\section{By Florina \\ Serbanescu, Paul \\ Stupp and \\ Charles Westoff}

Florina Serbanescu is senior health scientist, and Paul Stupp is a statistician-both in the Division of Reproductive Health, Centers for Disease Control and Prevention, Atlanta, GA, USA. Charles Westoff is professor emeritus of demographic studies and sociology, Office of Population Research, Princeton University, NJ, USA.
Most transition countries of Eastern Europe and the former Soviet Union have fertility rates lower than the typical rates in Western Europe and well below the replacement level of 2.1 births per woman. ${ }^{1,2}$ One of the principal proximate determinants of fertility decline in these countries has been the use of abortion on request during the first trimester of pregnancy.

In 1920, Russia became the first country to legalize abortion, doing so well before Western European countries. After the Socialist revolution, abortion on request was the main fertility control method in the Soviet Union. Even between 1936 and 1955, when abortion was legally available only to women with certain narrowly defined medical indications, medical providers and traditional practitioners performed many clandestine abortions. ${ }^{3}$ The procedure became broadly legal again in the Soviet Union in 1955. Until recently, abortion was the principal fertility control method throughout the Soviet bloc countries, and it continues to be widely used.

Currently, the abortion rates in several Eastern European and Central Asian countries are among the highest in the world. ${ }^{4,5}$ A high proportion (42-66\%) of pregnancies in these countries are unintended, and the great ma-

\footnotetext{
*The surveys were conducted in Armenia, Azerbaijan, Georgia, Kazakhstan, Kyrgyzstan, Moldova, Romania, Russia, Turkey, Turkmenistan, Ukraine and Uzbekistan.
}

jority (82-93\%) of unintended pregnancies end in elective abortion. ${ }^{6}$ Although almost all abortions in these countries are performed in health facilities, they are not completely risk-free; approximately $5-16 \%$ of abortions in Eastern Europe result in complications requiring treatment and in long-term consequences. ${ }^{5}$ Further, an estimated $26 \%$ of maternal deaths in the region are abortionrelated, compared with $13 \%$ worldwide. ${ }^{7}$

The Republic of Georgia, formerly part of the Soviet Union, has for more than a decade had one of the highest abortion rates in the world. Data from Demographic and Health Surveys (DHS) and Reproductive Health Surveys (RHS) indicate that from 1996 to 1999, the reported total abortion rate in Georgia-3.7 abortions per woman-was the highest among 12 Eastern European and Central Asian countries. ${ }^{* 2,6}$ During the same period, Georgia also had the lowest proportion of women using contraceptives (25\%). ${ }^{8}$ A subsequent RHS in Georgia, conducted in 2005 , showed that the prevalence of modern contraceptive use had increased by $12 \%$ (from $25 \%$ to $28 \%$ ) and that the abortion rate had declined by $16 \%$ (from 3.7 to 3.1 abortions per woman); nonetheless, Georgia continues to have the world's highest documented total abortion rate. ${ }^{9}$

The recent availability of high-quality RHS data provides the opportunity to document levels of contraceptive use and induced abortion in Georgia with more accuracy than 
was previously possible. Survey estimates of contraceptive prevalence are more accurate than estimates based on service statistics, which count only women attending facilities that provide family planning services. Survey-based estimates of the number of abortions in Georgia are seven times the official values, ${ }^{9}$ indicating problems with the government system for collecting abortion data. Omissions and misclassifications of abortions in the health information system are likely rooted in the traditional Soviet tendency to underreport unfavorable statistics. The prolonged transition to a market economy has further weakened abortion reporting, as underfunded state health facilities are less able than before to record and report abortion procedures, and the private health sector, which provides fewer than $3 \%$ of abortion services, ${ }^{8,9}$ does not usually report official statistics. Furthermore, a small fraction of abortions are obtained outside medical facilities and remain uncounted in the health information system.

Many complex factors influence national abortion rates. Social norms, fertility preferences, social and economic factors, access to clinical services, and availability and use of effective family planning methods all affect a country's reproductive health indicators. The high abortion rate in Georgia, coupled with rapid changes over the past decade in the social, political and economic environment and in health service delivery, offers an opportunity to assess changes in women's reproductive health and the interplay between contraceptive use and abortion rates.

We have done this using two approaches. The first employs a decomposition method that partitions changes in abortion rates into the proportion due to changes in the prevalence of use of modern and traditional contraceptives, and the proportion due to changes in contraceptiveuse-specific abortion rates (i.e., abortion rates among modern contraceptive users, among traditional contraceptive users and among nonusers). Contraceptiveuse-specific abortion rates are largely determined by the risk of contraceptive failure and the subsequent likelihood of pregnancy termination, according to type of method.

To further explore the interplay between abortion and contraceptive use, we examined abortion rates among users and nonusers with different risks of unintended pregnancy using a methodology developed by Westoff. ${ }^{2}$ Finally, we discuss the applicability of these methodologies in estimating the potential reductions in unintended pregnancy and the subsequent need for abortion in Georgia under different scenarios.

\section{Study Setting}

Situated between the Black Sea and the Caucasus Mountains, Georgia is a gateway between Asia and Europe. Ethnic Georgians represent 84\% of the population; Armenians and Azeri are the largest ethnic minority groups. Women of reproductive age (15-44) make up 23\% of the population of 4.4 million. ${ }^{10}$

Since the dissolution of the Soviet Union, Georgia has faced more than a decade of socioeconomic and political transition. The government has attempted to implement major reforms, including a health sector reform initiated in 1995. Progress has been uneven, however, because of the ongoing civil war with the separatist regions of Abkhazia and South Ossetia, the country's crumbling infrastructure and the economic collapse that occurred after the loss of Moscow's financial support.

Health care costs account for a decreasing proportion of public expenditures (3.6\% in 2004), resulting in the underfunding of medical facilities, including those providing family planning and reproductive health services. ${ }^{11}$ Once the main source of reproductive health research and policy development for the entire Soviet Union, Georgia now has poorer maternal and infant health indicators than it did during the Soviet era. ${ }^{12}$ Health care reforms supported by international donors have only recently increased women's access to modern contraceptives and other reproductive health services.

Abortion has long been legal, readily available, affordable (the average cost per procedure was US\$12.50 in 1999 and US\$16.00 in 2005) and widely practiced in Georgia. ${ }^{8,9}$ The abortion law, relatively unchanged since the update of the Soviet law in 1987, grants women the right to an abortion without restriction as to reason during the first 12 weeks of pregnancy and permits pregnancy terminations on medical and social grounds up to 22 weeks' gestation. ${ }^{13}$ In contrast, the availability of highquality contraceptive methods has been limited until recently, and the average monthly out-of-pocket cost for contraceptives, although reduced by half between 1999 and 2005 (from about US\$8 to US\$4.30), is still high for some users. ${ }^{8,9}$ Currently, Georgia does not have a national family planning program, and neither state nor private health insurance packages include family planning provisions. All family planning activities are maintained through donor support, primarily from the United States Agency for International Development (USAID) and the United Nations Population Fund (UNFPA). ${ }^{14}$ Since 1999, both agencies have invested heavily in building capacity, providing free contraceptive supplies, integrating contraceptive services into primary care, training family planning providers, providing services to remote areas, minorities and internally displaced families, and funding information, education and communication efforts.

\section{METHODS}

\section{Sample}

The Georgian Ministry of Health conducted the first Reproductive Health Survey in collaboration with the Georgian National Center for Disease Control between November 1999 and April 2000; the two agencies repeated this nationally representative household survey in March-July 2005. The reproductive health division of the United States Centers for Disease Control and Prevention (CDC), USAID and UNFPA provided technical assistance with the survey design, sampling, questionnaire development, training, data processing and analysis. A detailed de- 
scription of the survey methodology is available in previous publications. ${ }^{8,9}$

The surveys included nationally representative samples of women aged 15-44 (7,798 in 1999 and 6,376 in 2005). Trained interviewers conducted confidential, in-person interviews using standardized questionnaires to collect information on women's marital and cohabitation history, their pregnancy history (including pregnancies ending in induced abortion) and the intendedness of all pregnancies that ended during the five years before the survey. The surveys also included a comprehensive module on family planning knowledge, use, intentions, attitudes and opinions. Both surveys provided a month-by-month calendar in which women recorded their pregnancies, marital status, periods of contraceptive use and reasons for discontinuing contraceptive use during the five years preceding the survey. A detailed description of the survey methodology and comprehensive tabulated data are provided in the final survey reports. ${ }^{8,9}$

\section{Analytic Methods}

- Decomposition of change method. To examine how variations in contraceptive-use status and use-specific abortion rates have contributed to the decline in abortion in Georgia, we used a decomposition method originally described by Kitagawa ${ }^{15}$ that separates the difference between two rates into two components: the part of the difference caused by changes in the composition of one or more factors in the population under study, and the part caused by changes in factor-specific rates. In countries where fertility preferences and patterns are relatively stable, as in Georgia, increases in contraceptive use and contraceptive effectiveness lead to declines in abortion. ${ }^{16}$ In such settings, the overall abortion rate can be expressed as the weighted average of the abortion rates of all contraceptive-use groups in the population (modern method users, traditional method users and nonusers), with weights equal to the relative sizes of these groups. A change in the abortion rate over time, then, can be caused by changes in the composition of the population by contraceptive-use status, by changes in abortion rates among subgroups of contraceptive users and nonusers, or both. As noted earlier, among users, contraceptive-use-specific abortion rates are determined primarily by rates of contraceptive failure and propensity to rely on abortion once an unintended pregnancy occurs; among nonusers, they reflect the likelihood of pregnancy and abortion propensity.

Thus, in this study, the difference in abortion rates among married women between 1999 and 2005 is expressed as the sum of a first component that captures the effect of change in contraceptive-use status and a second component that reflects the effect of changes in contraceptive-use-specific rates of abortion. We calculated abortion and contraceptive prevalence rates for five-year periods in order to relate contraceptive use to abortion during the same time intervals. Although the demographic characteristics (e.g., age, marital status, education, socioeco- nomic status) of the population of reproductive-age women did not change significantly between 1999 and 2005, contraceptive prevalence rates and use-specific abortion rates may vary by these characteristics. Moreover, in specific subgroups, changes in contraceptive use and usespecific abortion rates may differ from those for the entire population of women of reproductive age. For example, the impact of group-specific increases in contraceptive use on the abortion rate may be cancelled out by higher usespecific abortion rates. To examine disparities in the interplay between contraceptive use and abortion, we performed similar decompositions of the changes in abortion rates among subgroups of women stratified by their background characteristics.

For this analysis, we used women's calendar histories of pregnancy and contraceptive events for two 60-month periods: November 1994-October 1999 and March 2000February 2005. We verified the consistency of abortion reporting in the calendar histories using data from lifetime pregnancy histories provided elsewhere in the questionnaire; only pregnancy terminations reported in both sections were included in the analyses. For each of the two periods, we evaluated rates of abortion and contraceptive use among married women by age, parity, education, residence and socioeconomic status. We confined the analysis to married women because surveys indicate that fewer than 3\% of Georgian women report premarital sexual experience, and because the reported use of contraceptives and experience with abortion among unmarried women are extremely low. Furthermore, married women constitute the conventional denominator for the contraceptive prevalence rate, one of the indicators used by the United Nations and other organizations to monitor improvements in maternal health.

We first calculated general marital abortion rates, defined as the number of abortions obtained by married women in a 60-month period divided by the number of married-woman-years. * We further calculated contraceptive use-specific general marital abortion rates according to the type of contraceptive used (modern, traditional or none) before a conception that resulted in an induced abortion. Finally, we calculated period-specific contraceptive prevalence rates for married women as the total of all months of use of specific methods (traditional, modern or none) divided by the number of months in which they were married during each 60-month period.

We separated the difference in the overall general marital abortion rates into components attributable to changes in the composition of women according to their contraceptive-use status and to changes in the contraceptive-

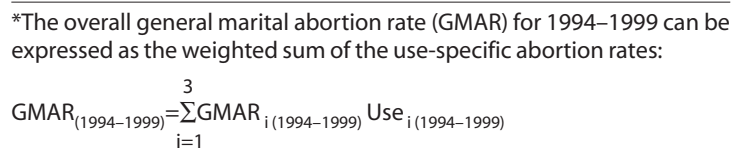

where $i=1,2$, or $3 ; 1=$ modern methods, $2=$ traditional methods and $3=$ no contraceptive use; and "Use $\mathrm{i}$ " represents the proportion of time that women were in use status "i." 
TABLE 1. Selected characteristics of women aged 15-44, Georgia Reproductive Health Survey, 1999 and 2005

\begin{tabular}{|c|c|c|c|c|c|}
\hline Characteristic & $\begin{array}{l}1999 \\
(\mathrm{~N}=7,798)\end{array}$ & $\begin{array}{l}2005 \\
(\mathrm{~N}=6,376)\end{array}$ & Characteristic & $\begin{array}{l}1999 \\
(\mathrm{~N}=7,798)\end{array}$ & $\begin{array}{l}2005 \\
(\mathrm{~N}=6,376)\end{array}$ \\
\hline $\begin{array}{l}\text { DEMOGRAPHIC } \\
\text { Age }\end{array}$ & & & $\begin{array}{l}\text { REPRODUCTIVE } \\
\text { Medians }\end{array}$ & & \\
\hline $15-19$ & 20.0 & 18.7 & Age at first intercourse & 21.5 & 21.3 \\
\hline $20-24$ & 16.8 & 17.7 & Age at first marriage & 21.6 & 21.6 \\
\hline $25-29$ & 15.6 & 16.0 & Age at first birth & 23.0 & 23.2 \\
\hline 30-34 & 15.9 & 14.9 & & & \\
\hline $35-39$ & 17.5 & 15.2 & Percentages & & \\
\hline $40-44$ & 14.3 & 17.6 & $\begin{array}{l}\text { Sexually active in past } 30 \text { days } \\
\text { Sexually active daily/nearly daily }\end{array}$ & 48.9 & 47.3 \\
\hline Marital status & & & in past 30 dayst & 31.8 & 31.2 \\
\hline Married & 60.8 & 59.5 & Women aged $15-24$ who have had & & \\
\hline Previously married & 6.0 & 5.8 & premarital sex & 1.4 & 2.5 \\
\hline \multirow[t]{2}{*}{ Never married } & 33.3 & 34.7 & Currently pregnant or postpartum & 7.2 & 7.1 \\
\hline & & & Married women who want no more children & 55.2 & 55.0 \\
\hline No. of living children & & & Pregnancies that are unintended $\neq \S$ & 63.1 & 62.4 \\
\hline 0 & 39.6 & 41.0 & Unintended pregnancies that & & \\
\hline 1 & 14.8 & 16.3 & end in abortion‡§ & 95.8 & 96.2 \\
\hline 2 & 31.3 & 30.3 & & & \\
\hline \multirow[t]{2}{*}{$\geq 3$} & 14.3 & 12.3 & Means & & \\
\hline & & & Duration of breast-feeding (mos.) & 10.6 & 10.1 \\
\hline Residence & & & Total fertility rate $\neq$ & 1.84 & $1.56^{*}$ \\
\hline Urban & 56.3 & 54.9 & Total wanted fertility rate $\neq$ & 1.79 & $1.53^{*}$ \\
\hline Rural & 43.7 & 45.1 & Total induced abortion rate $\ddagger$ & 3.7 & $3.1^{*}$ \\
\hline Ethnicity & & & CONTRACEPTIVE & & \\
\hline Georgian & 82.9 & 87.0 & Using any contraceptive method & 24.7 & $28.4^{*}$ \\
\hline Azeri & 8.9 & 5.2 & Married & 40.5 & $47.3^{*}$ \\
\hline Armenian & 4.6 & 5.4 & Previously married & 2.7 & 4.8 \\
\hline Other & 3.6 & 2.4 & Never married & 0.0 & 0.2 \\
\hline Education & & & Using modern contraceptive method & 12.1 & $16.1^{*}$ \\
\hline$<$ secondary & 16.7 & 16.3 & Married & 19.8 & $26.6^{*}$ \\
\hline Secondary & 33.4 & 27.4 & Previously married & 2.7 & 4.8 \\
\hline Technicum & 23.8 & 21.4 & Never máried & 0.0 & 0.2 \\
\hline \multirow[t]{2}{*}{ University/postgraduate } & 26.1 & 34.9 & & & \\
\hline & & & Has unmet need for contraception & 27.1 & $22.3^{*}$ \\
\hline Employed & & & Married & 44.1 & $37.0^{*}$ \\
\hline Yes & 22.5 & 21.1 & Previously married & 4.3 & 7.2 \\
\hline No & 77.5 & 78.9 & Never married & 0.1 & 0.0 \\
\hline Socioeconomic status & & & Method failure & & \\
\hline Low & 32.8 & 34.4 & for modern contraceptivest† & 6.0 & 4.4 \\
\hline Middle & 53.4 & 46.9 & for traditional contraceptivest† & 18.1 & 20.8 \\
\hline \multirow[t]{4}{*}{ High } & 13.9 & 18.8 & $\begin{array}{l}\text { Likelihood of abortion after } \\
\text { modern method failure }\end{array}$ & 83.0 & 78.8 \\
\hline & & & Likelihood of abortion after traditional & & \\
\hline & & & method failure & 90.6 & 89.7 \\
\hline & & & $\begin{array}{l}\text { Ilkeilnood of abortion arter pregnancy } \\
\text { among nonusers }\end{array}$ & 60.0 & $56.3^{*}$ \\
\hline
\end{tabular}

*Difference between 1999 and 2005 is significant at $p<.05$. †Among women who had been sexually active in the past 30 days. ¥Data are for past 60 months (November 1994-October 1999 and March 2000-February 2005). §Data are for all pregnancies (births, abortions, miscarriages) in the past 60 months. $++F a i l u r e$ rates are 12-month life table estimates using 60-month periods. Note: Women in consensual unions are categorized as married.

use-specific general marital abortion rates.*

We calculated estimated standard errors of the rate differences between the 60-month periods to account for the cluster design used in both surveys. The standard errors were determined using the "jackknife" method, which calculates variation in estimates by recalculating indicators while removing one sample point at a time. ${ }^{17}$

-Westoff method. In a separate analysis, we applied Westoff's

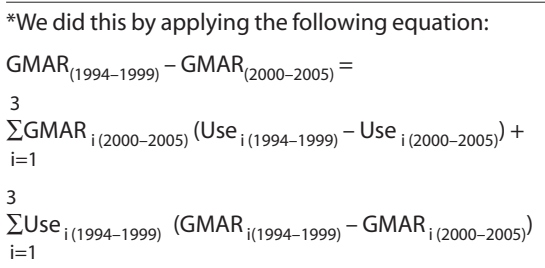

model to examine the risks of unintended pregnancy and subsequent abortion by use of modern contraceptives, by use of traditional contraceptives and by nonuse of contraceptives. These risks were calculated for the 12-month period prior to each survey. ${ }^{\dagger}$ Details of this approach are described elsewhere. ${ }^{18}$ The main aim of the model is to estimate average rates of unintended pregnancy among women with different types of exposure to the risk of such pregnancies and to formulate hypothetical changes in the abortion rate

†Specifically, the analysis focuses on women's month-by-month histories from November 1998 to October 1999 for the 1999 survey and from March 2004 to February 2005 for the 2005 survey. We excluded data from the months when the fieldwork was conducted and from women aged 15 at the time of the interview to ensure that all women in the sample contributed equal lengths of exposure during the 12 months preceding each survey. 
under various scenarios of contraceptive use and nonuse.

The Westoff model classifies monthly exposures to the risk of unintended pregnancy by contraceptive-use status (use of modern methods, use of traditional methods and nonuse) and further partitions the nonuse group into four subgroups: nonusers who were at high risk of unintended pregnancy because they were fecund and sexually active, did not want to become pregnant and were not using any method of pregnancy prevention;* nonusers who had a low risk because they or their partners were subfecund or infecund, or because they had not had sexual intercourse in the past month; nonusers who had no risk of unintended pregnancy because they were trying to conceive, were intentionally pregnant or were insusceptible to pregnancy because they had recently given birth to a wanted child; and nonusers who had never had sex.

Women were classified into these nonuse subcategories according to their status at the time of the interview. Ideally, nonusers should be classified by category of risk for each month during the period of analysis; like other largescale surveys, however, the RHS did not collect monthly data on reasons for nonuse. Therefore, we used a woman's status during the month of the interview as a proxy for her status during the 12 months preceding the survey.

Pregnancy rates were calculated for the women in each contraceptive-use group and nonuse subgroup by dividing the number of pregnancies by months of exposure. Pregnancies among contraceptive users included both unintended pregnancies that had occurred while the women were using contraceptives (i.e., method failure) and those that occurred during the first month after they discontinued contraceptive use for reasons other than to become pregnant. The total of all unintended pregnancies was divided by the number of months of use of modern or traditional methods to obtain the use-specific pregnancy rates. The pregnancy rate in each subgroup of nonusers was defined as the number of all pregnancies to women in the subgroup during the 12-month period divided by the aggregate number of months of contraceptive nonuse during the same period. To predict category-specific abortion rates and the general abortion rate, pregnancy rates were multiplied by the category-specific propensity to abort the pregnancy. While the use of shorter time intervals to calculate event rates would have better captured the current risk of unintended pregnancy, particularly among nonusers, a 12-month history was the shortest period we could use to observe a sufficient number of events that would yield robust estimates.

\section{RESULTS}

In general, the 1999 and 2005 samples had similar background characteristics and sexual and reproductive behaviors (Table 1). In both surveys, about a third of respondents were young adults (aged 15-24), three-fifths were in marital or cohabitating relationships and two-fifths

*This is equivalent to the DHS definition for having an unmet need for family planning and includes pregnant and recently postpartum (i.e., not yet menstruating) women whose pregnancies were unwanted or mistimed and occurred while the women were not using contraceptives.
TABLE 2. Percentage of women aged 15-44 using contraceptives, by method, according to marital status, Georgia Reproductive Health Survey, 1999 and 2005

\begin{tabular}{|c|c|c|c|c|c|c|c|c|}
\hline \multirow[t]{2}{*}{ Method } & \multicolumn{4}{|l|}{1999} & \multicolumn{4}{|l|}{2005} \\
\hline & $\begin{array}{l}\text { All } \\
(\mathrm{N}= \\
7,798)\end{array}$ & $\begin{array}{l}\text { Married } \\
(\mathrm{N}= \\
5,177)\end{array}$ & $\begin{array}{l}\text { Previously } \\
\text { married } \\
(\mathrm{N}=517)\end{array}$ & $\begin{array}{l}\text { Never } \\
\text { married } \\
(\mathrm{N}=2,104)\end{array}$ & $\begin{array}{l}\text { All } \\
(\mathrm{N}= \\
6,376)\end{array}$ & $\begin{array}{l}\text { Married } \\
(\mathrm{N}= \\
4,119)\end{array}$ & $\begin{array}{l}\text { Previously } \\
\text { married } \\
(\mathrm{N}=386)\end{array}$ & $\begin{array}{l}\text { Never } \\
\text { married } \\
(\mathrm{N}=1,871)\end{array}$ \\
\hline Any & 24.7 & 40.5 & 2.7 & 0.0 & 28.4 & $47.3^{*}$ & 4.8 & 0.2 \\
\hline Modern & 12.1 & 19.8 & 2.7 & 0.0 & 16.1 & $26.6^{*}$ & 4.8 & 0.2 \\
\hline IUD & 5.9 & 9.7 & 0.7 & 0.0 & 7.0 & 11.6 & 0.5 & 0.0 \\
\hline Condom & 3.9 & 6.3 & 1.1 & 0.0 & 5.3 & 8.7 & 2.0 & 0.2 \\
\hline Pill & 0.6 & 1.0 & 0.0 & 0.0 & 1.9 & 3.2 & 1.0 & 0.0 \\
\hline \multicolumn{9}{|l|}{ Female } \\
\hline sterilization & n 1.0 & 1.6 & 0.9 & 0.0 & 1.4 & 2.2 & 0.0 & 0.0 \\
\hline Spermicide & 0.1 & 0.1 & 0.0 & 0.0 & 0.5 & 0.9 & 1.0 & 0.0 \\
\hline Injectable & 0.0 & 0.0 & 0.0 & 0.0 & 0.0 & 0.0 & 0.2 & 0.0 \\
\hline Other & 0.6 & 1.0 & 0.0 & 0.0 & 0.0 & 0.0 & 0.0 & 0.0 \\
\hline Traditional & 12.6 & 20.7 & 0.0 & 0.0 & 12.3 & 20.7 & 0.0 & 0.0 \\
\hline Withdrawal & 6.4 & 10.5 & 0.0 & 0.0 & 6.6 & 11.2 & 0.0 & 0.0 \\
\hline $\begin{array}{l}\text { Periodic } \\
\text { abstinence }\end{array}$ & 6.2 & 10.2 & 0.0 & 0.0 & 5.7 & 9.5 & 0.0 & 0.0 \\
\hline None & 75.2 & 59.5 & 97.4 & 100.0 & 71.6 & 52.7 & 95.2 & 99.8 \\
\hline
\end{tabular}

*Difference between 1999 and 2005 is significant at $p<.05$. Note: Women in consensual unions are categorized as married.

were childless. Slightly fewer than half of the women resided in rural areas, and ethnic Georgians made up more than $80 \%$ of the population. Most women (83-84\%) had at least a secondary education ( 11 years of education completed), but relatively few were employed (21-23\%) or lived in households with high socioeconomic status (14-19\%).

The majority of women married early (median age at first marriage was 21.6 years in both surveys) and reported having their first sexual experience after marriage (not shown). Most initiated childbearing at an early age-median age at first birth was 23 in both surveys-and the samples reached peak fertility levels between ages 20 and 29 (not shown). Levels of current sexual activity, coital frequency, premarital intercourse, pregnancy or postpartum insusceptibility, and desire to end childbearing were similar in the two surveys.

Total fertility rates, although below replacement level (1.8 and 1.6 births per woman in 1999 and 2005, respectively), were still above levels found in most of Eastern Europe. ${ }^{5}$ In both surveys, almost two-thirds (62-63\%) of all pregnancies were unintended; nearly all unintended pregnancies (96\% each) ended in abortion, as did more than half of all pregnancies (not shown). Consequently, virtually all pregnancies carried to term were wanted births, and unwanted fertility represented only $2-3 \%$ of the total fertility rate.

Although the total abortion rate in Georgia declined from 3.7 to 3.1 abortions per woman between 1999 and 2005 , it remained twice as high as the total fertility rate (Table 1). Most abortions occurred among women aged 25-29 and 30-34 (not shown). The majority of women (79\% in 1999 and 82\% in 2005) agreed that a woman should always have the right to decide whether to carry a pregnancy to term; fewer than $2 \%$ believed that abortion 
TABLE 3. Rate of contraceptive use, by method type; general abortion rate; use-specific abortion rate, by method type; change in general abortion rate; and decomposition of change in general abortion rate-all among married women aged 15-44, according to selected characteristics, Georgia Reproductive Health Survey, 1999 and 2005

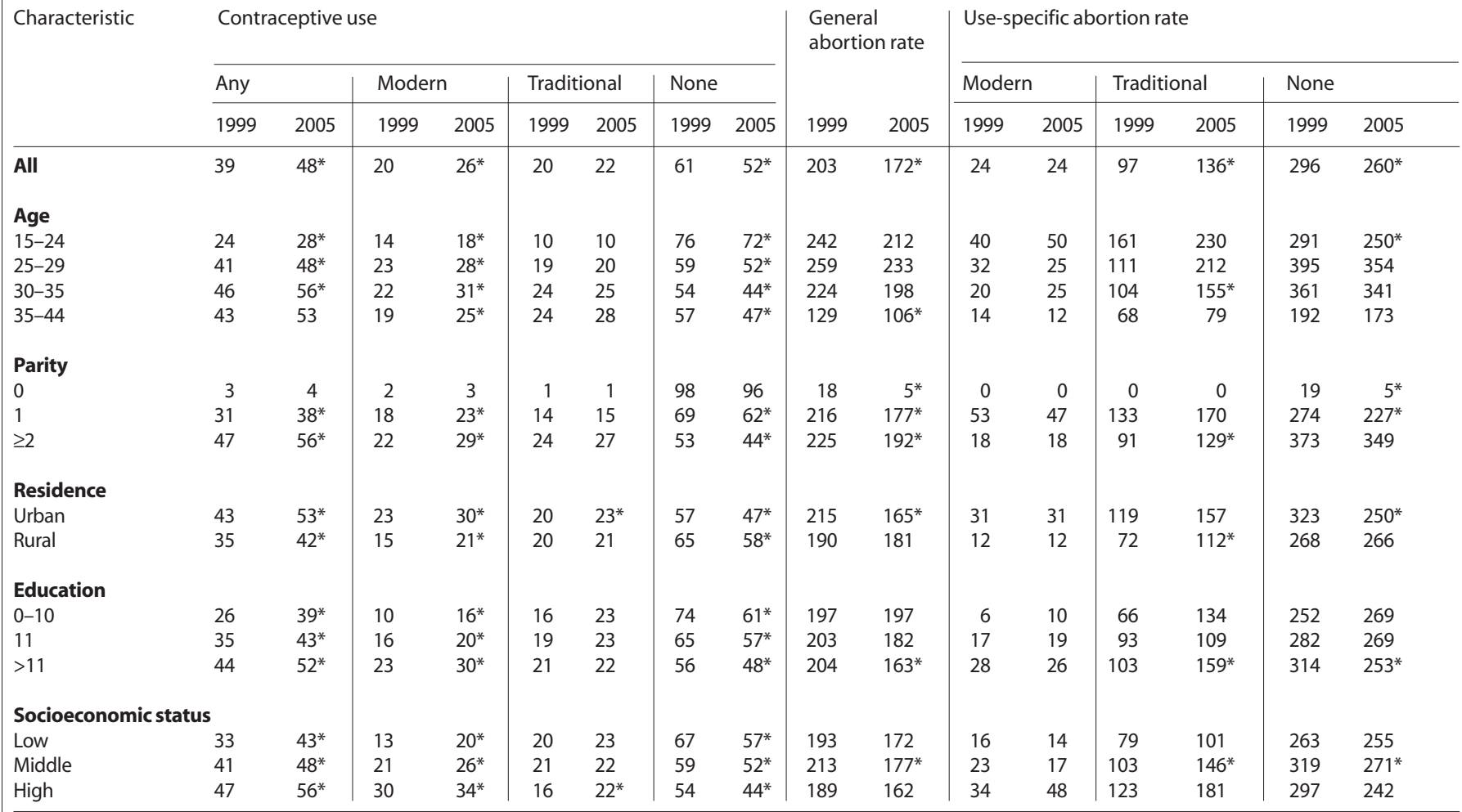

*Standard error of the difference in rates between 1994-1999 and 2000-2005 is significant at p<.05 as calculated using the jackknife repeated replication method. Notes: All data refer to the 60 months prior to the survey:November 1994-October 1999 for the 1999 survey and March 2000-February 2005 for the 2005 survey. Contraceptive use rates refer to rates of use per 100 married-

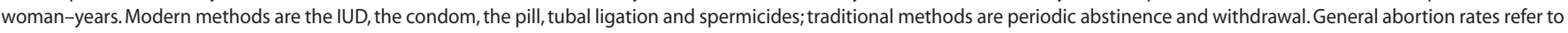

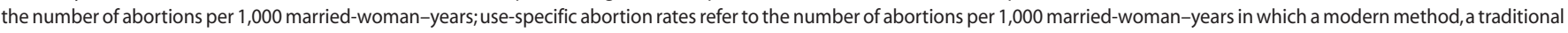
method or no method was used. All calculations use unrounded numbers; use of rounded numbers will yield slightly different results.

FIGURE 1. General abortion rate and prevalence of contraceptive use among married women aged 15-44, Georgia, 1995-2004

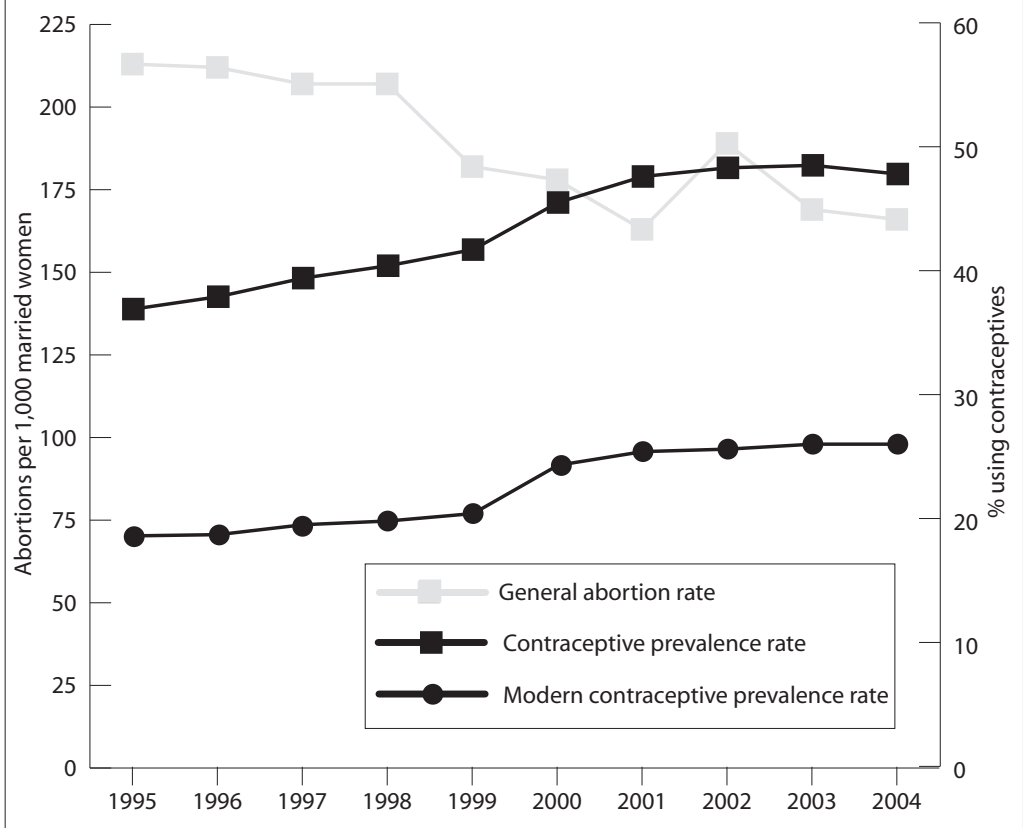

is never acceptable (not shown). Although virtually all abortions in Georgia are performed in medical facilities, the rate of abortion morbidity-despite a recent decline from $10 \%$ to $6 \%$ (not shown)-was higher than rates in developed countries. ${ }^{8,9}$

The prevalence of contraceptive use in Georgia is relatively low: In 2005 , only $28 \%$ of women were currently using a method (Table 1), and 58\% had never used any method (not shown). Almost all contraceptive users were married; prevalence of use was very low among previously married women (3-5\%) and almost nonexistent among never-married women. Nearly half (47\%) of married women were using contraceptives in 2005, compared with $41 \%$ in 1999 ; use of modern methods (27\%) was greater than that of traditional methods (21\%; not shown) in 2005. The 12-month failure rate (i.e., likelihood of becoming pregnant while using a contraceptive method) among users of modern methods declined slightly, although the difference did not reach statistical significance. The likelihood that a woman would end a pregnancy that resulted from contraceptive failure was very high in both surveys (79-91\%); the likelihood that she would abort a pregnancy that occurred while she was not using contraceptives was lower and declined between surveys (from $60 \%$ to $56 \%$ ). 


\begin{tabular}{|c|c|c|c|}
\hline \multirow[t]{2}{*}{ Characteristic } & \multirow{2}{*}{$\begin{array}{l}\text { Change in } \\
\text { general } \\
\text { abortion } \\
\text { rate }\end{array}$} & \multicolumn{2}{|c|}{ Decomposition of change } \\
\hline & & $\begin{array}{l}\text { Change in } \\
\text { contraceptive } \\
\text { use }\end{array}$ & $\begin{array}{l}\text { Change in } \\
\text { use-specific } \\
\text { abortion rate }\end{array}$ \\
\hline All & 31 & 17 & 14 \\
\hline \multicolumn{4}{|l|}{ Age } \\
\hline $15-24$ & 30 & 7 & 23 \\
\hline $25-29$ & 26 & 20 & 6 \\
\hline 30-34 & 26 & 28 & -2 \\
\hline $35-44$ & 23 & 14 & 9 \\
\hline \multicolumn{4}{|l|}{ Parity } \\
\hline 0 & 13 & 0 & 13 \\
\hline 1 & 39 & 10 & 29 \\
\hline$\geq 2$ & 33 & 29 & 4 \\
\hline \multicolumn{4}{|l|}{ Residence } \\
\hline Urban & 51 & 17 & 34 \\
\hline Rural & 9 & 17 & -7 \\
\hline \multicolumn{4}{|l|}{ Education } \\
\hline $0-10$ & 0 & 24 & -24 \\
\hline 11 & 21 & 16 & 5 \\
\hline$>11$ & 41 & 18 & 23 \\
\hline \multicolumn{4}{|c|}{ Socioeconomic status } \\
\hline Low & 21 & 20 & 1 \\
\hline Middle & 36 & 16 & 20 \\
\hline High & 27 & 11 & 16 \\
\hline
\end{tabular}

Between 1999 and 2005, women's reliance on modern contraceptive methods increased (Table 2, page 103). Among married women, increased use of IUDs, condoms and oral contraceptives resulted in significant improvements in the contraceptive prevalence rate. Use of traditional methods was unchanged during this period. The changes in the use of effective modern contraceptives coincided with a decline in abortion rates (Figure 1). Before 1999 , the abortion rate was relatively stable at approximately 200 abortions per 1,000 married women, and about $19 \%$ of married women were using a modern method of birth control. From 1999 onward, the use of modern methods and contraceptive methods in general increased, and the abortion rate began to decline.

\section{Decomposition of Change Method}

Between 1999 and 2005, the overall contraceptive prevalence rate among married women for the 60-month period before each survey increased by $23 \%$, from $39 \%$ to $48 \%$ (Table 3). In addition, the proportion using modern methods increased by $30 \%$, from $20 \%$ to $26 \%$. Modern method use increased for all subgroups except childless women, many of whom presumably wanted to become pregnant, and women aged 35-44. The 60-month general marital abortion rate (abortions per 1,000 woman-years) declined by $15 \%$ between 1999 and 2005, from 203 to 172; the relative declines were especially noteworthy among women aged 35-44 (18\%), childless women (72\%), urban residents (23\%) and women with a postsecondary education (20\%; calculations not shown).
As expected, the general marital abortion rate was inversely related to the prevalence and effectiveness of contraception in both time periods. The general marital abortion rate among women using modern methods-which did not change between 1999 and 2005-was the lowest (24 abortions per 1,000 woman-years) of the three contraceptive-use categories. The general marital abortion rate among women using traditional methods increased by 40\% (from 97 to 136 abortions per 1,000 woman-years) and was 4-6 times that for modern methods. The highest abortion rates were among nonusers, despite a decline from 296 to 260 abortions per 1,000 woman-years. In both time periods, general and use-specific abortion rates were higher among women who had had one or more previous births at the time of pregnancy termination than among those who were childless, suggesting that many families want to limit their number of children to one.

The difference between 1999 and 2005 in the periodspecific general marital abortion rate was 31 abortions per 1,000 woman-years. Using the decomposition method, we partitioned this difference into two components. Changes in the distribution of exposure time by categories of use and nonuse explained a reduction of 17 abortions per 1,000 woman-years, or 54\% of the decline; changes in the use-specific abortion rates contributed a reduction of 14 abortions per 1,000 woman-years, or $46 \%$ of the decline. However, the impact on the general abortion rate of the increased proportion of time women spent using contraceptives and the corresponding reduction in time spent as nonusers (from $61 \%$ to $52 \%$ ) differed by method category. Although the increase in prevalence of modern methods was not associated with any change in the use-specific abortion rate among these women, the abortion rate increased among users of traditional methods. Changes in contraceptive-use patterns were responsible for most of the decline in the abortion rates among women 25 and older ( $77 \%$ of the decline), women with at least two children (88\%), those with a completed secondary education but no postsecondary schooling (76\%) and women with low socioeconomic status (95\%; calculations not shown). Conversely, changes in abortion rates by category of use or nonuse were the main contributor to abortion decline among women aged 24 or younger (74\%), those with one or no children ( $74 \%$ and $100 \%$, respectively), urban women $(66 \%)$, women with postsecondary education (62\%), and women of middle and high socioeconomic status (58\% and 64\%, respectively). Among some subgroups (women aged 30-34 and rural women), the decline in the general marital abortion rate was entirely attributable to the increase in contraceptive use.

No change in the general marital abortion rate occurred among women with fewer than 11 years of education (197 abortions per 1,000 woman-years), despite a significant increase in their use of contraceptives. Decomposition showed that the increase in their contraceptive use, primarily of modern methods, was offset by changes in usespecific abortion rates in all categories of use, likely be- 
TABLE 4. Selected sexual and reproductive health outcomes among women aged 16-44, by women's contraceptive use status, method type and pregnancy risk, Georgia Reproductive Health Survey, 1999 and 2005

\begin{tabular}{lcc} 
Population/measure & 1999 & 2005 \\
\hline ALL WOMEN & & \\
Never had sex (\%) & 30.0 & 32.2 \\
Pregnancy rate (per 1,000 women) & 176 & 173 \\
Pregnancies aborted (\%) & 61.9 & 58.4 \\
Abortion rate (per 1,000 woman years) & 115 & 101
\end{tabular}

\section{CONTRACEPTIVE USERS}

All methods

$\%$ using a method

Annual method failure rate*

$\%$ of contraceptive failures aborted $t$

Modern methods

$\%$ using a modern method

Annual method failure rate*

$\%$ of contraceptive failures aborted $t$

Traditional methods

$\%$ using a method

Annual method failure rate*

$\%$ of contraceptive failures aborted $\dagger$

CONTRACEPTIVE NONUSERS

High risk of unintended pregnancy

$\%$ of women

Pregnancy rate

$\%$ of pregnancies aborted $\dagger$

Low risk of unintended pregnancy $\S$

$\%$ of women

Pregnancy rate

$\%$ of pregnancies aborted

No risk of unintended pregnancy††

$\%$ of women

Pregnancy rate

$\%$ of pregnancies aborted +

\begin{tabular}{|c|c|}
\hline 25.4 & 29.4 \\
\hline 0.158 & 0.14 \\
\hline 89.5 & 89.1 \\
\hline 12.4 & 16.7 \\
\hline 0.104 & 0.071 \\
\hline 89.0 & 89.7 \\
\hline 13.0 & 12.7 \\
\hline 0.103 & 0.157 \\
\hline 92.1 & 90.2 \\
\hline 16.2 & 11.1 \\
\hline 0.480 & 0.479 \\
\hline 82.5 & 80.9 \\
\hline 17.4 & 17.3 \\
\hline 0.045 & 0.051 \\
\hline 74.6 & 66.0 \\
\hline 11.0 & 10.1 \\
\hline 0.659 & 0.888 \\
\hline 11.5 & 16.7 \\
\hline
\end{tabular}

*Proportion of pregnancies resulting from method failure or following dis continuation with continued exposure to the risk of unintended pregnancy. †Abortion propensities are based on the preceding year's experience to permit sufficient time for a pregnancy conceived late in the year to be aborted. ‡Includes women who were unintentionally pregnant and postpartum women who had had an unintentional pregnancy. §Includes women who had not had sex in the past month. †tIncludes women who were seeking pregnancy, those who were intentionally pregnant and postpartum women who had had an intended pregnancy. Notes: All data refer to the 12 months prior to the survey: November 1998-October 1999 for the 1999 survey and March 2004-February 2005 for the 2005 survey.

cause of the combined effect of increased contraceptive failure and greater reliance on abortion in the most recent period.

\section{Westoff Method}

The Westoff approach examines outcomes by method category (among contraceptive users) and risk of unintended pregnancy (among nonusers). Almost a third of women interviewed in each survey reported that they had never had sex (Table 4). Twenty-nine percent of women had used some method of contraception during the year preceding the 2005 survey, while 38\% had not used any method.

Use of modern methods increased from $12 \%$ to $17 \%$ between 1999 and 2005, but use of traditional methods was stable at $13 \%$. The proportion of women who were non- users at high risk of an unintended pregnancy declined by almost a third (from 16\% to 11\%) between 1999 and 2005, while little or no change occurred in the proportions who were nonusers at low risk (17\% in both 1999 and 2005 ) or no risk (11\% in 1999 and 10\% in 2005) of becoming pregnant unintentionally.

The likelihood that a woman would have an abortion following an unintended pregnancy was very high among contraceptive users (approximately 90\% in both surveys) and nonusers at high risk of unintended pregnancy (81-83\%). Even among women classified as having no risk of unintended pregnancy (because they were intentionally pregnant or seeking to become pregnant), the likelihood of having had an induced abortion in the 12 months prior to the survey was substantial (12\% in 1999 and $17 \%$ in 2005). Because both the intendedness of a current pregnancy and future fertility preferences reflect attitudes during the month of the interview, and because pregnancy and abortion experiences were measured for the 12 months prior to the survey, the higher than expected likelihood of abortion in this group could be due to factors that changed between the time of the abortion and the time of the interview.

We constructed two flowcharts showing the aggregate contribution of users and nonusers to the general abortion rate during the 12 months preceding each survey, and the different pathways that women took to unintended pregnancy and abortion. Among all women aged 16-44, the 12-month abortion rate was lowest among users of modern methods (i.e., women who became pregnant while using these contraceptives or shortly after discontinuing use for any reason other than trying to get pregnant). Modern method users had an estimated 12 abortions per 1,000 woman-years in 1999 (Figure 2) and 11 abortions per 1,000 woman-years in 2005 (Figure 3). The corresponding figures among users of traditional methods were more than twice as high (25-26 per 1,000 woman-years).

Nonusers at high risk of unintended pregnancy had 64 and 43 abortions per 1,000 woman-years in 1999 and 2005 , respectively, while those at low risk had six abortions per 1,000 woman-years in both years. As expected, nonusers with no risk of unintended pregnancy had low abortion rates in both surveys ( 8 and 15 abortions per 1,000 woman-years, respectively).

Nonuse of contraceptives is the main determinant of the high abortion rate in Georgia. In 1999, 78 (68\%) of the 115 abortions estimated to have occurred per 1,000 women aged 16-44 were obtained by nonusers-64 (56\%) among those at high risk for unintended pregnancy, six (5\%) among those at low risk and eight (7\%) among those at no risk (Figure 2). Similarly, in 2005, 64 (64\%) of the 101 abortions estimated to have occurred per 1,000 women aged 16-44 occurred among nonusers-43 (43\%) among those at high risk for unintended pregnancy, six (6\%) among those at low risk and 15 (15\%) among those at no risk (Figure 3). Women who became pregnant while using traditional methods accounted for $22 \%$ and $26 \%$ of 


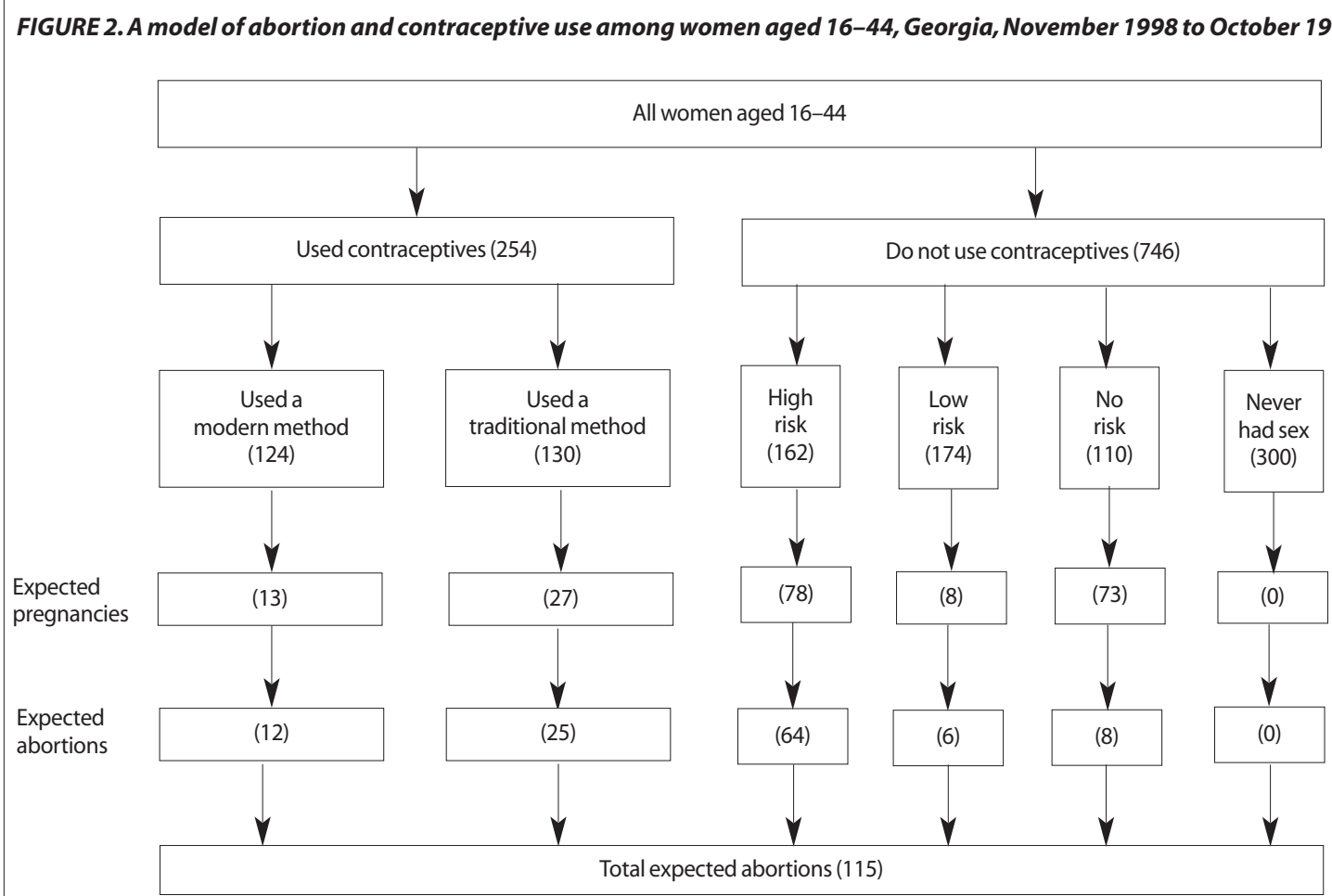

Notes: Figures in parentheses are rates per 1,000 woman-years. High risk, low risk and no risk refer to risk of unintended pregnancy.

abortions in 1999 and 2005, respectively; only about 11\% of abortions were obtained by users of modern methods (percentages calculated from data in Figures 2 and 3).

Thus, two main patterns of contraceptive behavior contribute to the high rate of unintended pregnancy and in- duced abortion in Georgia: nonuse of contraceptives by couples at high risk of unintended pregnancy, responsible for $43-56 \%$ of abortions; and use of traditional methods associated with high discontinuation and contraceptive failure rates, responsible for $22-26 \%$.

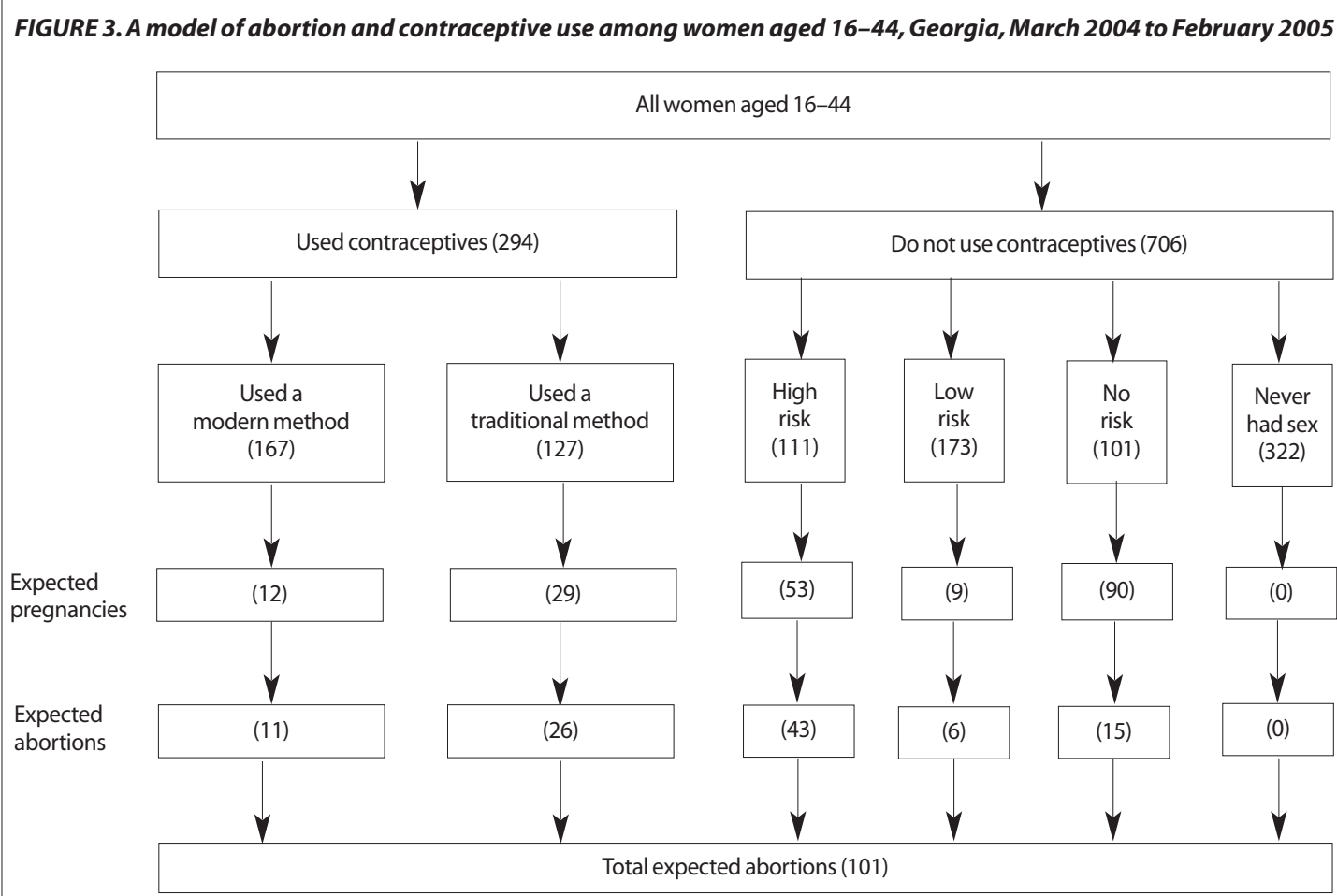

Notes: Figures in parentheses are rates per 1,000 woman-years. High risk,low risk and no risk refer to risk of unintended pregnancy. Sum of figures in risk groups does not equal the number of contraceptive nonusers because of rounding. 


\section{DISCUSSION}

Using data from two national, population-based reproductive health surveys conducted five years apart, we applied the decomposition method and the Westoff method to document the impact of contraceptive practice on the abortion rate. Both of our analyses showed that an increase in modern contraceptive use was accompanied by a significant decrease in the general abortion rate. Both documented that the majority of unintended pregnancies and subsequent abortions in Georgia occurred among women who were not using family planning.

The decomposition of change method allows the simultaneous evaluation of changes in abortion and contraceptive use and the separation of the abortion decline into two components-one reflecting the effect of change in the distribution of women by contraceptive use (54\% of the decline), the other capturing the effect of change in use-specific abortion rates ( $46 \%$ of the decline). The approach we used differs from those of previous studies, which used mathematical models or simulations to investigate the potential effect of changes in contraceptive use on abortion rates. To our knowledge, one-factor decomposition of change has not previously been applied to abortion rates, although it has been used to decompose changes in rates of other complex health outcomes. ${ }^{19-22}$ Few data sources have collected detailed histories of pregnancy, contraceptive use and marital status that were repeated over time in the same population.

Unlike the Westoff model, decomposition of change does not provide much detail about contraceptive nonusers. By limiting the analysis to married women, whose sexual and reproductive behaviors were relatively stable, we have minimized the combined influence of marriage, pregnancy and postpartum insusceptibility on the time spent at risk of pregnancy among nonusers, which allowed for a better comparison of their abortion rates. We hypothesize that the decline in the general marital abortion rate among nonusers was more likely caused by changes in the probability that these women would abort unintended pregnancies, rather than to changes in sexual activity and fecundability. Because it employs a stratified analysis by age, parity, residence, education and socioeconomic status, the decomposition of change method allows for a better examination of the trade-off between contraception and abortion among various demographic subgroups than does the Westoff model.

The Westoff model provides unique, detailed insights regarding the relative contribution of various subgroups to the risk of unintended pregnancy and subsequent abortion. Its main applicability is to aid analysts in hypothesizing different scenarios of change in contraceptive use and nonuse, applying the exposure-specific pregnancy rates observed at the time of the survey, and estimating future reductions in the risk of pregnancy and abortion implied by each assumption of contraceptive use and nonuse.

We compared the two approaches' data requirements, analytic characteristics, limitations and applications for assessing the public health impact of increased contraceptive use (Web Appendix Table 1). Both approaches require a detailed month-by-month calendar of pregnancy and contraceptive use, which allows the estimation of contraceptive, pregnancy and abortion rates for the years preceding the survey. Use of the five-year month-by-month calendar minimizes recall bias of both abortions and contraceptive use. ${ }^{23-26}$ While the decomposition method may be applied to different time intervals (using the same survey or two different surveys), analyses using the Westoff model are restricted to using only the most recent period within the calendar (preferably 12 months), because the approach classifies past events and exposures among nonusers of contraceptives according to their risk of unintended pregnancy (high, low or none). Women in the nonuse categories could have been at high, low or no risk for different durations and may have moved from one group to another in the recent past. For example, in this study, $12-17 \%$ of pregnancies in the past 12 months to women in the no-risk category ended in abortion, whereas this proportion should be close to zero in a more accurately predicted model. Given the limitations of the available data, our use of short time intervals to infer past risk of unintended pregnancy on the basis of a woman's current status is one way to minimize misclassification of nonusers.

Both approaches are equally affected by the extent to which women accurately report their pregnancies (particularly those that ended in abortion) and contraceptive use. Because abortion has long been legal, readily available and widely used in Georgia, normative bias associated with social stigma and abortion should be less prevalent than in other countries. The CDC surveys further reduce underreporting of abortion by collecting retrospective information in two sections of the questionnaire: the lifetime pregnancy histories (where the outcome is not discussed until the respondent has reported in detail on each pregnancy) and the month-by-month calendar of pregnancy and contraceptive experience. Only abortions reported in both sections were included in the analyses. Nonresponse bias was likely minimal, because the overall response rate in both surveys was $99 \%$, and the refusal rate for any individual question was less than $2 \%$. Reporting of both abortion experience and contraceptive use most likely differs by marital status, a bias we minimized in the decomposition of change analysis by limiting the study population to married women.

Because external validation of abortion reporting using official statistics is unsuitable in Georgia-the survey-based abortion rates we observed were seven times those of official reports-we examined the concordance of abortion reports in 1999 and 2005 by performing cohort and subgroup differentials analyses (not shown). Since both cohort-specific abortion rates (i.e., five-year age-specific abortion rates of the same age-cohort examined five years apart) and abortion differentials were remarkably consis- 
tent in 2005 and 1999, we conclude that the level of abortion reporting did not change significantly between the two surveys.

Another limitation of both analytic approaches is the categorization of all modern contraceptive users into a single group for whom effectiveness of contraceptive use and propensity to terminate unintended pregnancies represent averages across diverse methods. The validity of projected changes in the abortion rates under various scenarios may be less precise if the actual changes in method mix, failure rates and abortion propensities differ significantly from those we used, although our conclusions related to abortion changes would remain largely unaffected. More important, using either approach to estimate future gains associated with increased contraceptive use requires the assumption that the pregnancy rates observed among different groups of users and nonusers will remain stable. The fallacy of this assumption is indirectly documented by our analyses, which show that the largest share of abortions is accounted for by contraceptive nonusers and that the abortion rate among nonusers was lower in 2005 than in 1999 (with the largest reduction occurring among highrisk nonusers, according to the Westoff model). This suggests that future redistributions of nonusers to contraceptive-use groups would likely reduce the pregnancy rates among nonusers even further, perhaps because those with the highest risk of unintended pregnancy would be most likely to adopt contraception. In effect, future abortion declines due to contraceptive gains are likely to be less dramatic than those observed between 1999 and 2005 if the relative contributions of nonuse and contraceptive failure change, even if the propensity to terminate an unintended pregnancy remains relatively constant.

Both methodologies provide evidence for physicians, program planners, public health officials and international aid organizations that investment in increasing availability and use of modern family planning methods has a direct, measurable effect on abortion reduction. Both methodologies can be used to identify the subgroups for which focused interventions could have the most impact, which is key if Georgia is to attain its Millennium Development Goal targets for increased use of modern contraceptives $-36 \%$ of married women by 2010 and $55 \%$ by 2015.27

Georgian women experience very high rates of unintended pregnancy because many do not use contraceptives or use relatively ineffective methods. Encouragingly, the proportion of married women using modern methods was higher in 2005 than in 1999, and the monthly cost of contraception was lower. Efforts to prevent unintended pregnancies must reduce inequities in family planning access, method choice and information availability. The impact of expanding information about effective contraceptive methods and increasing their availability and use in high-risk and hard-to-reach areas needs to be assessed periodically to guide efforts to prevent unintended pregnancy and the resulting abortions in Georgia.

\section{REFERENCES}

1. Population Reference Bureau (PRB), 2006 World Population Data Sheet, Washington, DC: PRB, 2006.

2. Westoff CF, Recent Trends in Abortion and Contraception in 12 Countries, DHS Analytical Studies, Calverton, MD, USA: ORC Macro, 2005, No. 8

3. David HP, ed., From Abortion to Contraception: A Resource to Public Policies and Reproductive Behavior in Central and Eastern Europe from 1917 to the Present, Westport, CT, USA: Greenwood Press, 1999.

4. Henshaw SK, Singh S and Haas T, Recent trends in abortion rates worldwide, International Family Planning Perspectives, 1999 25(1):44-48.

5. Sedgh $G$ et al., Induced abortion: estimated rates and trends worldwide, Lancet, 2007, 370(9595):1338-1345.

6. Sullivan JM, Serbanescu F and Goldberg H, Abortion, in: Centers for Disease Control and Prevention (CDC) and ORC Macro, Reproductive, Maternal and Child Health in Eastern Europe and Eurasia: A Comparative Report, Atlanta, GA, USA: CDC; and Calverton, MD, USA: ORC Macro, 2003, pp. 35-50.

7. World Health Organization (WHO), Unsafe Abortion: Global and Regional Estimates of Incidence of Unsafe Abortion and Associated Mortality in 2000, fourth ed., Geneva: WHO, 2004.

8. Serbanescu F et al., Reproductive Health Survey, Georgia, 1999-2000: Final Report, Atlanta, GA, USA: Georgian National Center for Disease Control and CDC, 2001

9. Serbanescu F et al., eds., Reproductive Health Survey, Georgia, 2005 Final Report, Atlanta, GA, USA: Georgian National Center for Disease Control and CDC, 2007

10. State Department for Statistics, Georgian Ministry of Economic Development, Population of Georgia in 2002: Statistical Abstract, Tbilisi, Georgia: Georgian State Department for Statistics, 2003.

11. Georgian-European Policy and Legal Advice Center, National accounts and main trends, Georgian Economic Trends Quarterly Review. 2004, No. 4, pp. 9-15

12. Tsuladze G, Maglaperidze N and Vadachkoria A, 2004 Demographic Yearbook of Georgia, Tbilisi, Georgia: United Nations Population Fund, 2005

13. USSR Ministry of Health, Order no. 757, June 5, 1987; and Order no. 1342, Dec. 31, 1987

14. Hudgins T and Rao R, Republic of Georgia Contraceptive Availability Assessment: Final Report, Boston, MA, USA: John Snow International, 2004

15. Kitagawa EM, Components of a difference between two rates, Journal of the American Statistical Association, 1955, 50(272):11681194.

16. Marston C and Cleland J, Relationships between contraception and abortion: a review of the evidence, International Family Planning Perspectives, 2003, 29(1):6-13.

17. Korn EL and Graubard BI, Analysis of Health Surveys, New York: John Wiley \& Sons, 1999

18. Westoff CF and Serbanescu F, The Relationship Between Contraception and Abortion in the Republic of Georgia: Further Analysis of the Republic of Georgia Reproductive Health Surveys, 1999 and 2005, Calverton, MD, USA: Macro International, 2008.

19. Hsieh HL et al., Fetal death rate in the United States, 1979-1990: trend and racial disparity, Obstetrics \& Gynecology, 1997, 89(1):33-39.

20. Carmichael SL and Iyasu S, Changes in the black-white infant mortality gap from 1983 to 1991 in the United States, American Journal of Preventive Medicine, 1998, 15(3):220-227.

21. Yang Q, Greenland S and Flanders WD, Associations of maternal age- and parity-related factors with trends in low-birthweight rates: United States, 1980 through 2000, American Journal of Public Health, 2006, 96(5):856-861. 
22. Schempf AH et al., The contribution of preterm birth to the blackwhite infant mortality gap, 1990 and 2000, American Journal of Public Health, 2007, 97(7):1255-1260.

23. Coulter A et al., The ability of women to recall their oral contraceptive histories, Contraception, 1986, 33(2):127-137.

24. Wingo PA et al., The evaluation of the data collection process for a multicenter, population-based, case-control design, American Journal of Epidemiology, 1988, 128(1):206-217.

25. Magnani R, Rutenberg N and McCann HG, Detecting induced abortions from reports of pregnancy terminations in DHS calendar data, Studies in Family Planning, 1996, 27(1):36-43

26. Strickler JA et al., The reliability of reporting of contraceptive behavior in DHS calendar data: evidence from Morocco, Studies in Family Planning, 1997, 28(1):44-53.

27. Georgian Ministry of Health, Labor and Social Affairs, Georgia National Reproductive Health Policy, 2006, Tbilisi, Georgia: Government of Georgia, 2007

\section{RESUMEN}

Contexto: La tasa de aborto en la república de Georgia es la más alta documentada a nivel mundial. Se necesita de análisis basados en datos confiables para fundamentar con información los programas para prevenir los embarazos no planeados y el aborto.

Métodos: Datos de dos extensas encuestas nacionales de hogares realizadas en 1999 y 2005, se utilizaron para evaluar la relación entre el uso de anticoncepción y el aborto. Dos enfoques analíticos fueron aplicados. Primero, se estimó las tasas de aborto para tres subgrupos: usuarias de anticonceptivos modernos, usuarias de anticonceptivos tradicionales y mujeres que no eran usuarias de anticonceptivos. Posteriormente, se utilizó un método de descomposición para estimar qué proporción de los cambios en las tasas de aborto se debían a cambios en el uso de anticonceptivos, así como a cambios en las tasas de aborto específicas al uso y no uso de anticonceptivos. Segundo, se usó una metodología desarrollada por Westoff para examinar tasas de aborto en usuarias de anticonceptivos y en no usuarias, con diferentes riesgos de embarazo no planeado.

Resultados: Según los datos para los 60 meses antes de las dos encuestas, la prevalencia del uso de anticonceptivos en mujeres casadas aumentó en un $40 \%$ (de 20\% a 28\%) y la tasa de aborto en mujeres casadas disminuyó en un 15\% (de 203 a 172 abortos por 1,000 años-mujer) entre 1999 y 2005. Ambos enfoques analíticos demostraron que el no uso de algún método fue el principal determinante de la alta tasa de embarazo no planeado; y que el aumento en el uso de anticonceptivos modernos fue un factor que contribuyó significativamente a la reciente disminución en la tasa de aborto (lo que explica el 54\% de la disminución, según el análisis de descomposición).
Conclusiones: Los esfuerzos para aumentar la disponibilidad y uso de métodos modernos de planificación familiar en Georgia deben conducir a una disminución directa y medible de la tasa de aborto.

\section{RÉSUMÉ}

Contexte: Le taux d'avortement en République de Géorgie est le plus haut documenté au monde. Il importe de procéder à des analyses reposant sur des données fiables pour éclairer les programmes de prévention des grossesses non désirées et de l'avortement.

Méthodes: Les données de deux vastes enquêtes nationales menées auprès des ménages en 1999 et 2005 servent à évaluer le rapport entre la pratique contraceptive et l'avortement. Deux approches analytiques sont adoptées. Les taux d'avortement sont d'abord estimés pour trois sous-groupes: les utilisatrices de la contraception moderne, celles de la contraception traditionnelle et les non-utilisatrices. Une méthode de décomposition sert alors à estimer les proportions de changement des taux d'avortement imputables aux changements de pratique contraceptive et à ceux des taux d'IVG spécifiques de pratique ou nonpratique contraceptive. En second lieu, une méthodologie développée par Westoff sert à examiner les taux d'avortement chez les utilisatrices de la contraception et chez les non-utilisatrices à risques distincts de grossesse non planifiée.

Résultats: Entre 1999 et 2005, la prévalence contraceptive a augmenté de 23\% (de 39\% à 48\%) tandis que le taux d'avortement marital baissait de 15\% (de 203 à 172 avortements par millier de femmes-années). Les deux méthodologies démontrent que l'absence totale de contraception est le principal déterminant du haut taux de grossesses non planifiées en Géorgie et que l'augmentation de la pratique de la contraception moderne contribue significativement à la récente baisse de l'avortement (elle explique, d'après l'analyse de décomposition, 54\% du déclin enregistré).

Conclusions: Les efforts en faveur d'une plus grande disponibilité et pratique des méthodes modernes de planification familiale en Géorgie devraient mener à un déclin direct et mesurable du taux d'avortement.

\section{Acknowledgments}

The authors acknowledge input received at the IUSSP seminar Interrelationships Between Contraception, Unintended Pregnancy and Induced Abortion, held in Addis Ababa, Ethiopia, Dec. 1-3, 2008, where an earlier version of this article was presented.

Author contact:fserbanescu@cdc.gov 